\title{
NEW MULTIVARIATE EMPIRICAL PREDICTION EQUATION FOR RELATIVE FEED VALUE OF NATIVE GRASSES
}

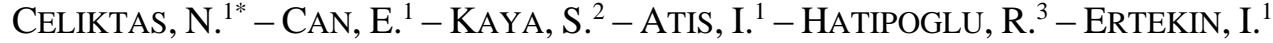 \\ ${ }^{I}$ Department of Field Crops, Agricultural Faculty of Mustafa Kemal University, Antakya, 31034 \\ Hatay, Turkey \\ (e-mails/ORCIDs: ecan69@hotmail.com/0000-0003-3530-6010; iatis15@hotmail.com/0000- \\ 0002-0510-9625; ibrahimertekin@mku.edu.tr/0000-0002-3030-8159) \\ ${ }^{2}$ Department of Animal Science, Agricultural Faculty of Mustafa Kemal University, Antakya, \\ 31034 Hatay, Turkey \\ (e-mail/ORCID: serafettinkaya@gmail.com/0000-0001-9744-8714) \\ ${ }^{3}$ Department of Field Crops, Agricultural Faculty of Çukurova University, Sarlçam, 01330 \\ Adana, Turkey \\ (e-mails/ORCIDs: rustu_hatipoglu@hotmail.com/0000-0002-7977-0782) \\ *Corresponding author \\ e-mail:nafizcel@hotmail.com; phone: +90-326-245-5845/11038; fax: +90-326-245-5832; \\ ORCID: 0000-0002-0467-1034
}

(Received $6^{\text {th }}$ Sep 2019; accepted $28^{\text {th }}$ Nov 2019)

\begin{abstract}
Relative feed value and structural mineral differentiation of native grasses and their relationships at different plant growth stages were studied to create a more informative multivariate model to predict relative feed value. The hierarchical clustering grouped the species and their growth stages under six distinct categories with their average relative feed values of 122.6, 108.6, 99.6, 90.3, 80.9 and 71.5. The principal component analyses for the relative feed value and the mineral composition of native grasses was efficient to classify the forages with the total explained variation of $63.69 \%$ with the first two principal components. The most important predictors for relative feed value were determined as nitrogen and potassium contents of the native grasses according to beta coefficients from the partial least square regression analyses. Three partial least square regression based new empirical equations for predicting the relative feed value were constructed by using the forage nitrogen content. The coefficients of determination $\left(\mathrm{R}^{2}\right)$ and the root mean square error of prediction (RMSEP) for the equations were 0.92, 0.35, 0.81 and 2.17, 11.29, 5.88, respectively. The Fisher's F test manifested that the actual and the predicted relative feed values were not different $(\mathrm{P}>0.05)$ for all three equations.
\end{abstract}

Keywords: forage quality index, mineral elements, pasture, plant growth stages, PLSR

\section{Introduction}

Reaching the optimum reflection of animal genetic potential on the phenotype is only possible with an accurate diet program. In order to achieve this, delicious and highly digestible, quality roughage above the maintenance requirement of the animal is an absolute necessity. This will also lead to economic farming via reducing concentrated feed because 60 to $70 \%$ of dairy or beef cattle production costs are concerned with feed inputs. Actually sustainable livestock farming requires the use of a pasture-based system. High-quality roughage feed from the pastures also encourages a healthy rumen flora by enhancing the effectiveness of the bacteria (Schroeder, 1996). This promotes nutrient intake and also conversion to energy.

In the formulation of diets for dairy cattle, the quality and the amount of forage needed to meet nutrient and fiber requirements must be considered in the first (Linn and Kuehn, 
1997). The fiber needed in rations for cud chewing and rumination is provided through forage. The feed requirement varies depending on both animal species and their physiological growth stages and with this aspect, there are many different criteria to express the quality of feed. Knowing this helps in forming the diet program and also foreseeing the management cost. Moreover, it is necessary to manage the natural ecosystems without any detriment for many years. Forage quality can be expressed with the subjective physical evaluations and also with the results of the chemical analysis, which entail more accurate assessments. The relative feed value (RFV) has become an important criteria for evaluating the quality of the forage. RFV is a forage quality index used widely for hay pricing. It is used for forage-quality education and also by seed producers to indicate variety improvement (Moore and Undersander, 2002) and it is an energy-based scale (Henning et al., 1999). Acid detergent fiber (ADF) estimates forage digestibility and neutral detergent fiber (NDF) provides an estimate for forage intake (Caddel and Allen, 1994). RFV is obtained on the basis of both intake and digestibility; thus, RFV reflects the forage quality in a single digit by using these two animal responses. However, the forage-quality parameters including the RFV are variable and almost everything can affect them in one way or another in native pastures. The RFV hay-grading system is based on the full-bloom alfalfa hay, which has an RFV of 100. However, grasses usually have higher concentrations of NDF than legumes at the same plant growth stages (Hodgson et al., 2014). But NDF is more digestible than alfalfa (Brown and Pittman, 1991; Ward, 2008). Therefore, comparing grasses with legumes using such a grading underestimates the nutritional value of high-quality grasses relative to legumes.

The minerals are key to many metabolic reactions most of the time. That is why the forage quality is assessed by the accumulation rate of the minerals in plant tissues one way or another. The amount of those minerals in grass tissues depend upon many factors including genetic capacity to take up minerals from the soil, availability of minerals in soil, stage of plant growth, climatic conditions, etc. (Kappel et al., 1983; Stone, 1994; Greene, 1997). Forage nutritive value is often evaluated by measuring such characteristics related to digestibility and intake. Whereas, the minerals that correlate with these factors should not be overlooked. Knowledge on plant nutrient characteristics and its relationship with RFV is vital. Also, RFV ignores the important variations in economic value caused by variation in crude protein (CP) concentrations (Weiss et al., 2012). Consequently, creating more descriptive equations for different forages is important for an accurate pricing or planning of feeding.

Chemometry is a useful tool to explain the best such relations by processing the chemical results with mathematics and statistics. Multivariate modelling that is one of the important chemometric applications is a statistical tool that uses multiple variables to predict the possible outputs. Partial least-squares regression (PLSR) has been one of the most widely applied multivariate calibration method because of the quality of calibration models produced and the ease of their implementation (Hopke, 2003). It is appreciable for constructing predictive models when the explanatory variables are many and highly collinear (Yeniay and Göktaş, 2002).

The study presented in this paper discusses the variations of relative feed values (RFVs) and the mineral compositions of the herbage obtained from some important native grasses at different plant growth stages, their relationships and the possibilities of producing new empirical equations for predicting RFV by applying multivariate analyses (MVA) and their literature based comparative accuracy. 


\section{Materials and methods}

\section{Grass samples}

Some of the native grass species from the natural pastures (between $36^{\circ} 13^{\prime} 04^{\prime \prime}$ $36^{\circ} 29^{\prime} 55^{\prime \prime} \mathrm{N} / 36^{\circ} 11^{\prime} 37^{\prime \prime}-36^{\circ} 14^{\prime} 59^{\prime \prime} \mathrm{E}, 80 \mathrm{~m}$ average altitude) of Amik Plain located at the east Mediterranean coastal region of Turkey were evaluated in the study. Eight pasture sites with different directions and geog. exposure were determined for sampling (Fig. 1).

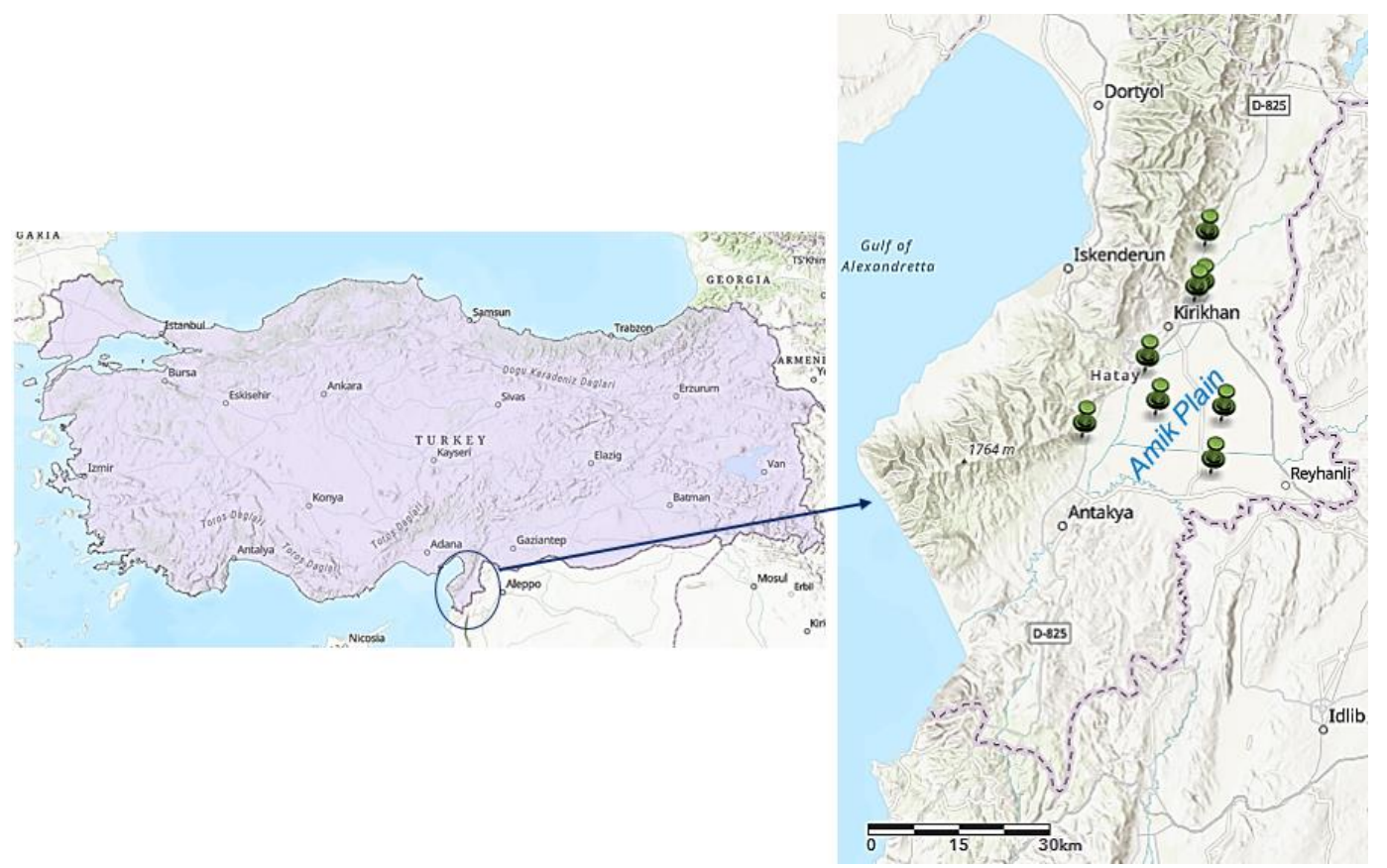

Figure 1. The map of sampling sites from the Amik Plain of Hatay province

The climate of the site is a Mediterranean-type with mild, wet winters and warm to hot dry summers. The seven cool-season $\mathrm{C} 3$ grasses and four warm season $\mathrm{C} 4$ grasses were studied (Table 1). Five phenological stages being vegetative (VEG), stem elongation (STE), head emergence and flowering (HEF), developing seed stalks (DSS) and seed ripening (SER), adapted from Cogswell and Kamstra (1976), were included in the study for relative feed values (RFV) and mineral composition.

\section{Sample preparation, chemical analyses and calculations}

Grass sampling at each plant growth stages was accomplished in the same habitat in the year of 2016. Harvested aboveground materials from 3 individual clones of each species at the stages of phenology described above were washed with continuously flowing tap water and rinsed with distilled water for possible contaminants, oven-dried at $70{ }^{\circ} \mathrm{C}$ for $48 \mathrm{~h}$ and homogenized by particle size reduction $(<0.5 \mathrm{~mm})$. Neutral detergent fiber (NDF) and acid detergent fiber (ADF) analyses were performed as described by Goering and Van Soest (1970). Digestible dry matter (DDM), Dry matter intake (DMI) and Relative feed value (RFV) were estimated by the equations given below suggested by Undersander et al. (1993):

$$
\mathrm{DDM} \%=88.9-(0.779 \times \mathrm{ADF} \%)
$$




\section{DMI $\%$ of body weight $=120 \div \mathrm{NDF} \%$}

$$
\mathrm{RFV}=(\mathrm{DDM} \times \mathrm{DMI}) \div 1.29
$$

Powdered samples were digested with $\mathrm{HNO}_{3}+\mathrm{HClO}_{4}$ mixture (Jones et al., 1991) and analyzed for calcium $(\mathrm{Ca})$, magnesium $(\mathrm{Mg})$, potassium $(\mathrm{K})$, phosphorus $(\mathrm{P})$, iron $(\mathrm{Fe})$, copper $(\mathrm{Cu})$, manganese $(\mathrm{Mn})$, and zinc $(\mathrm{Zn})$ contents by inductively coupled plasma atomic emission spectroscopy (ICP-AES Varian Liberty Series II). Nitrogen (N) content of the samples was determined by the Kjeldahl method (Kjeldahl, 1883). All chemical analyzes were performed with three repetitions.

Table 1. The investigated grass species and the abbreviations for plant scientific names

\begin{tabular}{l|c|c}
\hline \multicolumn{2}{c|}{ Species } & Abbreviation \\
\hline & Tall fescue (Festuca arundinaceae L.) & Feau \\
& Tor-grass (Brachypodium pinnatum (L.) Beauv.) & Brpi \\
& Timothy (Phleum pretense L.) & Phpr \\
Cool-season C3 grasses & Orchard grass (Dactylis glomerata L.) & Dagl \\
& Smooth brome (Bromus inermis Leyss.) & Brin \\
& Perennial ryegrass (Lolium perenne L.) & Lope \\
& Bulbous barley (Hordeum bulbosum L.) & Hobu \\
\hline \multirow{2}{*}{ Warm-season C4 grasses } & Coolatai grass (Hyparrhenia hirta (L.) & Hyhi \\
& Pallis grass (Paspalum dilatatum Poir.) & Padi \\
& Yellow bluestem (Bothriochloa ischaemum (L) Keng) & Bois \\
& Red oat grass (Themeda triandra Forss.) & Thtr \\
\hline
\end{tabular}

\section{Data analysis}

Significance in differences of RFV means for all species at whole plant growth stages were evaluated by Duncan multiple comparison tests at the $1 \%$ significance level with SPSS software (v24 for Windows; IBM, New York, USA). Hierarchical clustering analysis was applied to group the species according to periodically changing RFV with Ward method by using the software JMP 13 (SAS Institute Inc. Cary, North Carolina, USA). Principal component analyses (PCA) which is the most commonly used ordination technique was applied to observe the behavior of RFV and the mineral compositions of native grasses at different phenological stages by reducing the dimensionality of the original data matrix. To determine the key mineral(s) affecting the RFV and the quantitative relationships between them (constructing an empirical multivariate model), partial least-squares regression (PLSR) analysis was applied. The performance of the developed empirical equations was evaluated with the coefficients of determination $\left(\mathrm{R}^{2}\right)$, root mean square error of prediction (RMSEP) and literature based comparison of the predicted RFVs. Differences between the actual RFV from the open access literature and the predicted ones obtained in the study were compared with Fisher's $F$ test. The chemometric software XLSTAT v2016 (Addinsoft Inc., New York, USA) was used for PCA and PLSR analyses. 


\section{Results and discussion}

\section{$R F V$ differentiation depending on the plant growth stages}

Mean relative feed values (RFV) of the native grass species averaged over five plant growth stages are presented in Table 2. As shown in Table 2 differences between the RFV of the native species were significantly important.

Table 2. Relative feed values (RFV) of the native grass species as an average of five plant growth stages

\begin{tabular}{c|c|c|c|c}
\hline Species & Range & Mean & Std. dev. & MAD $^{\mathbf{2}}$ \\
\hline Feau & $79.31-103.49$ & $94.67 \mathrm{~b}^{1}$ & 8.05 & 7.02 \\
Brpi & $70.33-88.54$ & $79.13 \mathrm{de}$ & 6.24 & 5.65 \\
Phpr & $88.78-112.87$ & $102.30 \mathrm{a}$ & 7.68 & 6.92 \\
Dagl & $72.68-103.79$ & $84.89 \mathrm{c}$ & 9.36 & 8.17 \\
Brin & $87.02-100.96$ & $93.26 \mathrm{~b}$ & 4.33 & 3.68 \\
Lope & $71.20-123.34$ & $103.20 \mathrm{a}$ & 15.45 & 11.70 \\
Hobu & $66.24-130.82$ & $95.21 \mathrm{~b}$ & 19.66 & 16.09 \\
\hline Hyhi & $65.04-87.84$ & $76.33 \mathrm{e}$ & 8.29 & 7.37 \\
Padi & $65.79-89.78$ & $80.18 \mathrm{~d}$ & 7.91 & 6.24 \\
Bois & $68.91-82.58$ & $76.69 \mathrm{e}$ & 4.36 & 3.75 \\
Thtr & $70.12-88.78$ & $78.01 \mathrm{de}$ & 6.18 & 5.76 \\
\hline
\end{tabular}

LSD: 3.362

${ }^{1}$ Differences between the groups comprising different letters in the same column is statistically significant $(\mathrm{P}<0.01)$

${ }^{2} \mathrm{MAD}=$ Mean absolute deviation

The highest value of RFV (103.20) was determined for Perennial ryegrass but it was clustered with the same statistical group with Timothy. Coolatai-grass was evaluated as the species having the lowest RFV with 76.33 as an average of whole vegetation. However, the species of yellow bluestem, tor-grass and red oat grass were clustered together with coolatai-grass, as well. As it is expected, the RFV decreased with the advancing plant growth stages (Fig. 2).

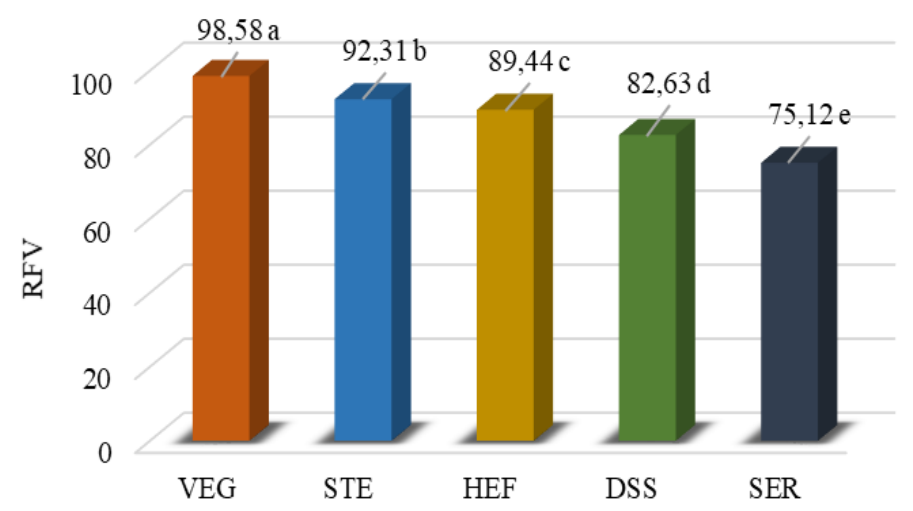

Figure 2. Relative feed value (RFV) at different plant growth stages of native grasses ( $L S D=1.199, P<0.01)$ (VEG: Vegetative, STE: Stem elongation, HEF: Head emergence and flowering, DSS: Developing seed stalks, SER: Seed ripening) 
The highest RFV was detected for the earlier phenological stages. Generally, the cool season grasses had better RFV than the warm season grasses; however, RFV of the species significantly varied depending on their growth stages (Fig. 3).

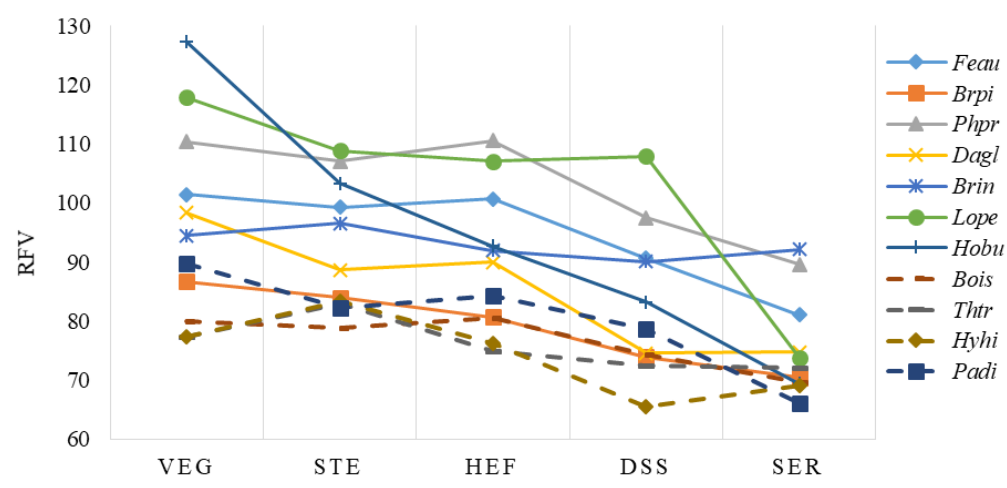

Figure 3. Differentiation of relative feed value (RFV) of native grasses depending on the plant growth stages (Dashed lines indicate the warm season C4 grasses)

In other words, the quality parameters were substantially under the influence of the stage of maturity. Actually, the information about mentioned fluctuations is more valuable for pasture management since the grazing period do not cover whole growth stages. In that respect, while the highest mean values were observed from perennial ryegrass (Lope) without any small deviation till DSS, it reached one of the lowest averages at the end stage with a severe reduction. In fact, this is a critical stage for pasture plants when the grazing process should be terminated to avoid some physiological damages to the plants. Therefore, the decline on RFV at this critical stage gives some advantages to plants in respect to storing nutrients and seed maturation. On the other hand, the decline for Timothy ( $\mathrm{Phpr}$ ) was not obvious as in perennial ryegrass in maturity stages. In this respect, the most remarkable reduction was recorded for bulbous barley (Hobu). It had the lowest RFV at SER with a distinctive reduction while it stood the highest at the beginning of the vegetation. However, it was one of the good species with a moderate RFV index as an overall average. On the other hand, it was consequently determined as the worst species in terms of dry matter digestibility together with tall fescue, which also has good RFV index (data not shown). Something similar can also be said for orchard grass ( $\mathrm{Dagl}$ ). Tall fescue (Feau) seemed to be the most stable species in terms of RFV differentiation throughout the maturity stages. The investigated four warm season C4 grasses produced the worst RFV indexes even in VEG stage. This is an expected result since the higher temperatures increase the lignocellulosic structure and reduce the soluble carbohydrates (Pearson and Ison, 1997). Therefore, the C4 species start to accumulate more lignin at earlier stages. The constellation plot in Figure 4 summarizes the clusters formed with the RFV differentiation of the species at different plant growth stages. The hierarchical clustering grouped the species and their growth stages under six distinct clusters (Clu). The HobuVEG and LopeVEG were constituted the first cluster (Clu1) with the highest average RFV (122.6). The warm season grasses were mostly clustered in Clu5 and Clu6 with the worst RFV (80.9 and 71.5, respectively). It is clear that the later stages of the cool season grasses such as FeauSER or PhprSER were closely aggregated with the very early stages of the warm season grasses. 


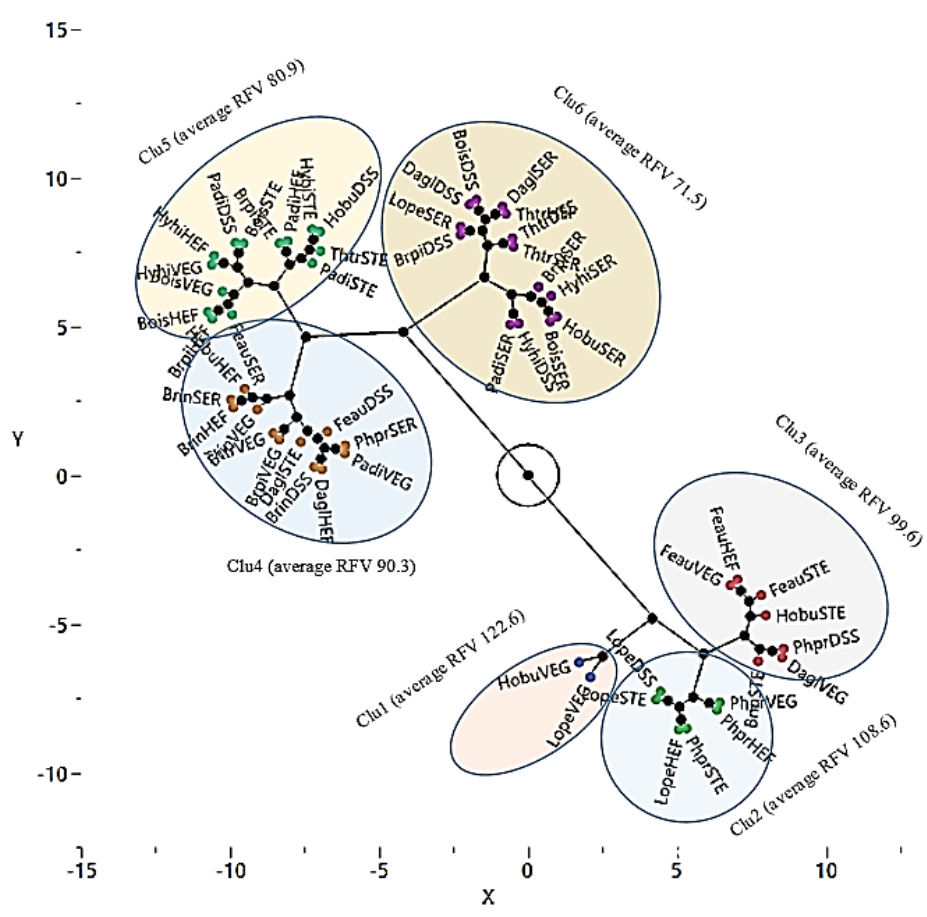

Figure 4. The hierarchical clusters (Clu) formed with the relative feed value (RFV) differentiation of the plant species at different plant growth stages (VEG: Vegetative, STE: Stem elongation, HEF: Head emergence and flowering, DSS: Developing seed stalks, SER: Seed ripening)

High animal gains require an adequate nutrition program. Hence, matching the forage quality to animal nutritional needs greatly increases the productivity. Producing highquality forage requires the knowledge of the factors that affect forage quality and management accordingly. Stage of maturity when harvested or grazed is the most important factor affecting the forage quality. Relative feed value (RFV) is an index that makes it possible to compare forages based on their digestibility and intake. Forage quality is highest when pasture plants are young and vegetative. Timothy (Phpr) species reached the superior RFV index at HEF stage, even higher than the index calculated at its VEG while the other species tend to decrease at HEF (Fig. 3). This is because of the extremely poor cellulosic structure of timothy at mentioned stage. It is one of the fastgrowing species that accumulates more cytoplasmic compounds (Poorter and Bergkotte, 1992; Niemann et al., 1992). Pasture or forage quality is very closely related with the amount of leaves (Lacefield et al., 2012). The leaf/stem ratio of the species at harvest; however, is one of the major determiners of lignocellulosic structure along with RFV. Ball et al. (2001) propounded that the higher the leaf content, the higher the forage quality since the NDF in legume or grass leaves is significantly more digestible than NDF in stem tissue (Hoffman et al., 2003). Timothy (Phpr) is a leafy species, which translates to high digestibility and intake (Peeters, 2004). It has a higher capacity to accumulate watersoluble carbohydrates (WSC) like fructose. Humphreys (1989) reported a positive correlation between WSCs and dry matter digestibility DMD. Likewise, Pearson and Ison (1997) attributed that the reason of the lower digestibility of C4 plants is related to a rapid decrease in soluble carbohydrate content as a result of the increased temperature. WSCs are also an indicator of palatability of the forages (Mayland et al., 2000). Sturla (1960) 
indicated that Timothy as the most palatable species followed by perennial ryegrass. Thus, the first four growth stages of Timothy species were clustered in the best quality region (Clu2 and Clu3). Therefore, it is possible to infer that the higher the RFV in forages, the more digestible and palatable they become.

In fact, forage plants differentiate so rapidly that it is possible to detect significant declines in forage quality every two or three days (Fulgueira et al., 2007). Schroeder (1996) pointed out as well that quality declines four to five times a day in RFV in the spring. That is why the rapid quality changes make the cutting or grazing time critical especially on fast-growing species. Our results targeted bloom stage (HEF) as having the maximum quality and yield for most of the investigated native species. Similarly, Lacefield et al. (2012) indicated that the RFV index of cool season grasses at vegetativeboot and boot-head stages were 101-122 and 84-101 respectively. As it is seen in Figure 4 , the first three clusters, even the fourth cluster, are within the mentioned range with their average RFV (Clu1: 122.6, Clu2: 108.6, Clu3: 99.6 and Clu4: 90.3 respectively). The results of the chemical analyses in the current study covers the entire biomass analyses of the native species. However, the animals in pastureland selectively graze native plant parts. Hence, native grasses are able to produce higher than expected animal gains estimated by the whole plant analyses. Therefore, comparison of RFV of the native species with the other forages may result in misevaluation. Because of this, the nutritional value of the higher quality native grasses may be underestimated. Moore and Undersander (2002) indicated that a current equation to predict DMI is based on the assumption of NDF intake with a constant $1.2 \%$ of body weight. Whereas, they emphasized that "the NDF intake is not exactly a constant $1.2 \%$ of body weight". NDF intake is variable for grasses and legumes fed alone. That is why, the authors argue that different equations may be needed for alfalfa, cool-season grasses, warm season grasses, grass/legume mixtures, corn silage, etc.

\section{The multivariate relationship between $R F V$ and mineral contents}

The mineral composition of the native grass forages at different growth stages are given in Table 3.

Table 3. Values of macro and microelement composition as an average of 11 native grass species and five plant growth stages

\begin{tabular}{l|c|c|c|c|c}
\hline \multicolumn{2}{c|}{ Macro and micro elements } & Range & Mean & Std. dev. & MAD $^{\mathbf{1}}$ \\
\hline \multirow{5}{*}{ Macro minerals $\left(\mathrm{g} \mathrm{kg}^{-1}\right)$} & $\mathrm{N}^{2}$ & $5.82-26.12$ & 14.78 & 5.51 & 4.80 \\
& $\mathrm{P}$ & $1.05-4.92$ & 2.75 & 1.02 & 0.84 \\
& $\mathrm{~K}$ & $5.63-19.33$ & 12.88 & 3.73 & 3.19 \\
& $\mathrm{Ca}$ & $1.96-13.66$ & 5.27 & 2.34 & 1.61 \\
& $\mathrm{Mg}$ & $0.87-2.57$ & 1.75 & 0.47 & 0.40 \\
\hline \multirow{4}{*}{ Micro minerals (mg kg-1) } & $\mathrm{Zn}$ & $12.04-57.10$ & 22.20 & 7.12 & 4.76 \\
& $\mathrm{Cu}$ & $3.87-18.89$ & 8.65 & 2.85 & 2.15 \\
& $\mathrm{Fe}$ & $75.39-702.67$ & 190.25 & 102.76 & 64.61 \\
& $\mathrm{Mn}$ & $12.41-191.74$ & 64.43 & 48.54 & 37.93 \\
\hline
\end{tabular}

${ }^{1} \mathrm{MAD}=$ Mean absolute deviation

${ }^{2} \mathrm{~N}$ (Nitrogen), $\mathrm{P}$ (phosphorus), K (potassium), Ca (calcium), Mg (magnesium), Zn (zinc), Cu (copper), $\mathrm{Fe}$ (iron) and $\mathrm{Mn}$ (manganese) 
The range and the mean values are the averages of eleven species and five plant growth stages. The mineral content of forages varies and depends primarily on forage species and their growth stages (Rayburn, 1997). Principal component analysis (PCA) and partial least square regression (PLSR) analyses were carried out on the relationship among RFV, mineral contents, grass species and growth stages and the results were presented below.

\section{PCA analyses}

PCA analyses showed both the mentioned mineral differentiations and the relationships between the RFV of native grass species at different growth stages (Fig. 5).

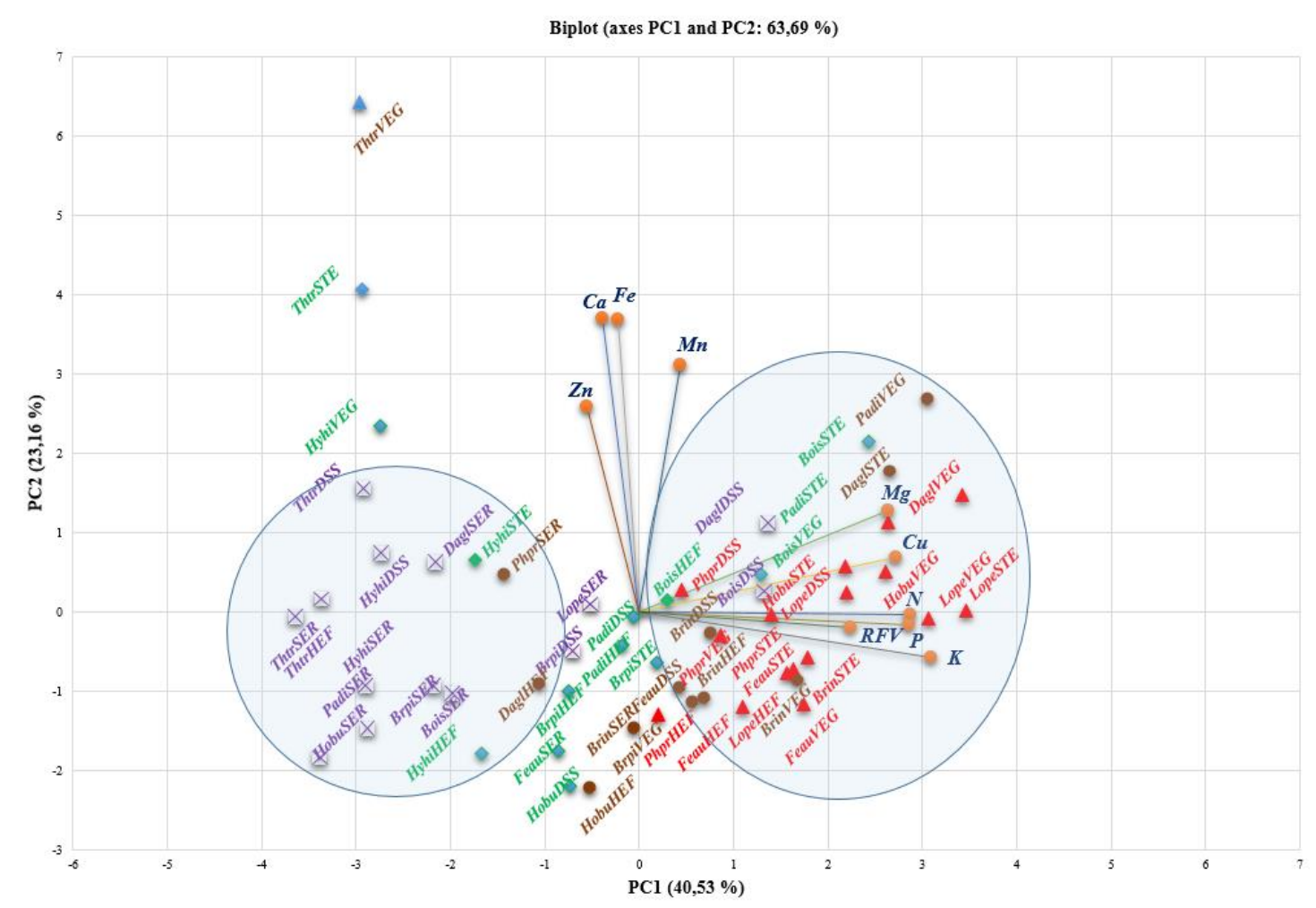

Figure 5. Principal component analyses (PCA) for relative feed value (RFV) and the mineral composition of native grass species at different plant growth stages. (The markers " $\Delta$ " represent the clusters Clu1, Clu2 and Clu3, "O"Clu4, "จ" Clu5 and "×” Clu6)

The PCA was effective to classify the samples explaining the total variation of $63.69 \%$ with the first two principal components (PC). The clusters of the forage samples of different species and growth stages that had higher RFV and assigned as Clu1, Clu2 and Clu3 in Figure 4 were located up on the positive side of the PC1 axis. However, it is seen that the clusters in Figure 3 are dispersed and the new elements are added to the area that we can define as quality zone or some of them are located beyond the boundaries of this zone. The coefficients of the eigenvectors for nitrogen (0.423), phosphorus (0.421) and potassium (0.456) were found to be about same on PC1 axes. That means the contribution of these elements on PC1 for the explanation of the variation (40.5\%) is about equal. PC1 axis represents the forages that have higher minerals of $\mathrm{N}, \mathrm{P}, \mathrm{K}, \mathrm{Cu}$ and $\mathrm{Mg}$ on their biochemical structure. So, the forages which had higher RFV accumulated higher 
amounts of these elements. As it is seen from the biplot graph, this region mostly covers the earlier plant growth stages. In this respect, the forages of perennial ryegrass (Lope) at VEG, STE and bulbous barley (Hobu) at VEG stage had good quality in view of both mineral composition and RFV. When the forages are evaluated only on the basis of RFV, the species and their growth stages contained within the clusters Clu1, Clu2 and Clu3 were prominent in view of quality (Fig. 4). Whereas, the multivariate relation, by adding the minerals, considered the components from Clu4 (especially DaglSTE, PadiVEG and BrinVEG), Clu5 (BoisSTE, PadiSTE and BoisVEG) and Clu6 (BoisDSS and DaglDSS) moved them to the quality zone. That means that while some of the forages such as the ones from the early phenological stages of yellow bluestem (Bois) and dallis grass (Padi) were underestimated before they will be evaluated with valuable cool season grasses in the new assessment. On the other hand, some of the components of Clu2 moved towards the border of the quality zone. The plant growth stage DSS was mainly clustered around the center of the biplot graph which expresses the lower RFV and mineral accumulation. The forage samples obtained from the latest stage of SER, which were aggregated under the cluster Clu6 (Fig. 4), were located around the negative regions of both PC1 and PC2 axis. The eigenvectors of the iron (0.546) and calcium (0.542) were similar on PC2 axis. Therefore, the negative region of the PC2 axes covers the species and plant growth stages that have both lover RFV and $\mathrm{Fe}, \mathrm{Ca}$ and $\mathrm{Zn}$ accumulation capacity. Even the other warm season grasses of coolatai grass (Hyhi) and red oat grass (Thtr) were evaluated as the poor RFV species and they have the important sources of the minerals $\mathrm{Fe}, \mathrm{Ca}, \mathrm{Zn}$ and $\mathrm{Mn}$ at earlier stages. Therefore, the versatile evaluation of any forage provided information that is more valuable to the pasture manager for managing the ration.

\section{PLSR-based new equation construction}

Partial least square regression (PLSR) was applied to relate and predict to RFV to structural mineral composition of the hay. The variable importance of the projection (VIPs) for each explanatory mineral elements showed that $\mathrm{N}, \mathrm{K}, \mathrm{Mg}$ and $\mathrm{P}$ contributed the most to the RFV (VIP>1) (Fig. 6).

On the other hand, Figure 7 shows the standardized coefficients, which provide a comparison of the relative weight of the variables on the RFV. The higher the coefficient, the greater the impression of the corresponding variable (Perez-Arevalo et al., 2015). Thus, the most important predictors for RFV were determined as $\mathrm{N}$ and $\mathrm{K}$ at $95 \%$ confidence interval.

In most of the studies related to forage quality, data related to protein content of forage are included. The Kjeldahl method (Kjeldahl digestion) is a very common method for the quantitative determination of nitrogen contained in organic substances developed by Johan Kjeldahl in 1883. Since the $16 \%$ of the protein is nitrogen, the protein content of any forage is mostly determined by multiplying the nitrogen content with a constant of 6.25 (Mariotti et al., 2008). The Kjeldahl protocol includes the steps digestion, distillation, and titration which require sophisticated equipment (Sáez-Plaza et al., 2013). It appears to be at least as a laborious protocol as the ones for other macro or microelements. However, the advantage of the nitrogen (or protein content) is that it is a very common forage quality data. Therefore, the PLSR based equations for predicting the RFV were constructed as N\% based. The equations and their prediction accuracy related statistics are given in Table 4. 


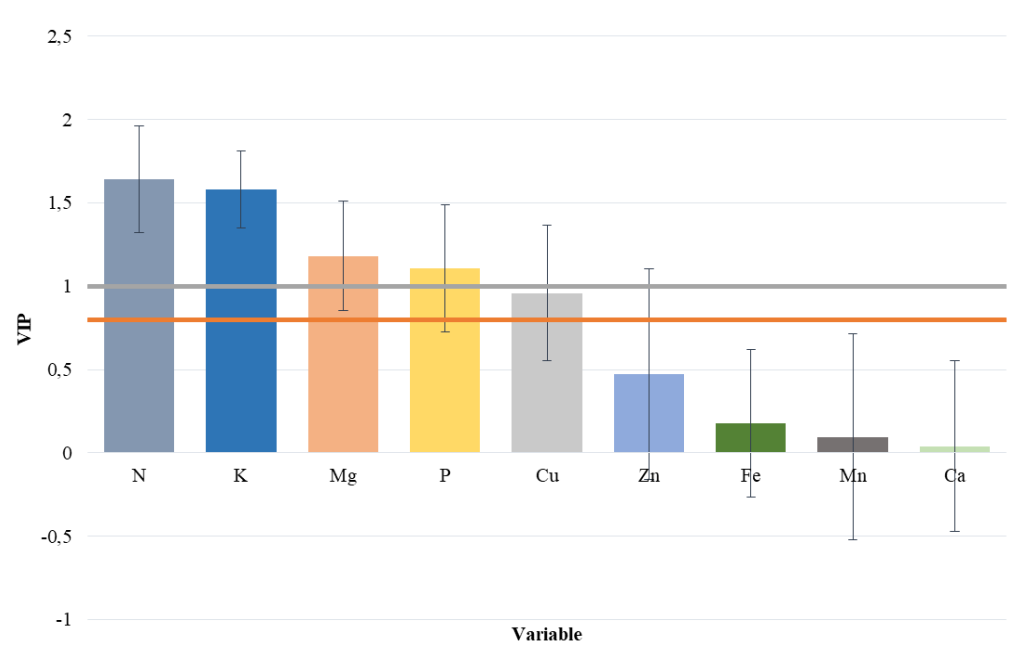

Figure 6. The variable importance of the projection (VIPs) from partial least squares regression (PLSR) analyses for each explanatory variable of relative feed value (RFV) at $95 \%$ confidence interval

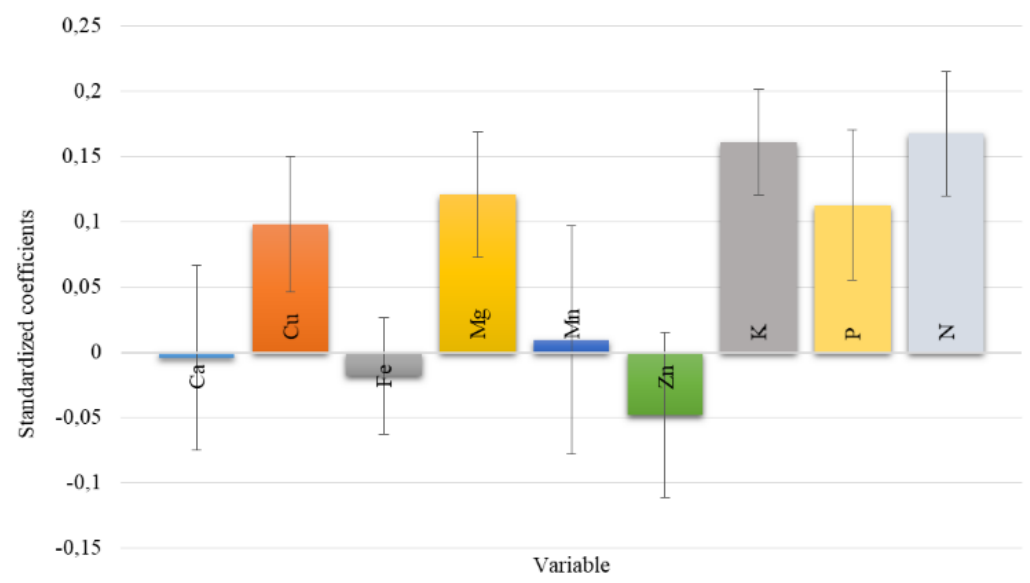

Figure 7. Standardized/beta coefficients from partial least squares regression (PLSR) model at 95\% confidence interval

Table 4. New PLSR based equations for predicting the RFV from forage nitrogen content along with the data range and the prediction accuracy statistics

\begin{tabular}{c|c|c|c|c|c}
\hline Equations & $\mathbf{n}$ & Range & Std. dev. & $\mathbf{R}^{2}$ & RMSEP \\
\hline (Eq.1) RFV=57.11+20.52 N\% & 5 & $\begin{array}{c}\text { RFV: } 75.12-98.58 \\
\text { N\%: } 0.88-1.84\end{array}$ & 2.80 & 0.92 & 2.17 \\
(Eq.2) RFV=65.20+15.07 N\% & 55 & $\begin{array}{c}\text { RFV: } 65.44-127.26 \\
\text { N\%: } 0.58-2.61\end{array}$ & 11.50 & 0.35 & 11.29 \\
(Eq.3) RFV=54.25+23.95 N\% & 106 & $\begin{array}{c}\text { RFV: } 65.04-123.84 \\
\text { N\%: } 0.52-2.43\end{array}$ & 5.94 & 0.81 & 5.88 \\
\hline
\end{tabular}


The empirical model Eq. 1 was constructed with the data produced by averaging the 165 data comprising 11 grass species, 5 phenological stages and 3 repetitions. Equation 2 is a model constructed from the average data of 11 species and 5 phenological stages whereas Equation 3 is based on an outlier or noisy data filtering of 165 samples empirically. As it seen in Table 4 despite data filtering, Equation 3 has the largest and best representing data range to the entire sample. Equation 1 has the higher coefficient of determination $\left(\mathrm{R}^{2}=0.928\right)$ with the lowest RMSEP value (2.17) that means the higher prediction accuracy. In fact, it includes the whole information about investigated species and plant growth stages. However, it reflects mainly the periodical differentiations of RFV. Multivariate modelling is highly sensitive to the existence of outliers within a dataset. Therefore, the prediction performance statistics of $\mathrm{R}^{2}$ and RMSEP for Equation 3 were increased with data preprocessing while they were quite low for the raw data in Equation 2. If the RMSEP value of Equation 2 was within the acceptable range, the lower $\mathrm{R}^{2}$ value may be ignored for a multivariate model. Nevertheless, it was the highest that means the predicted value can be out of range.

The estimation verification of the new equations was carried out by external validation test based on the data from literature. Table 5 shows the predicted RFVs for each equation with the open access literature notifications.

Table 5. The estimation verification of the new prediction equations by external validation test

\begin{tabular}{|c|c|c|c|c|}
\hline Reference & Hay type & Ref N\% ${ }^{+}$ & Ref RFV & Predicted RFV \\
\hline \multirow{4}{*}{ Lacefield et al., 2012} & \multirow{2}{*}{ Cool season grasses } & $\begin{array}{l}\text { Veg/boot } \\
1.92-2.56\end{array}$ & $101-122$ & $\begin{array}{c}96.5-109,6^{1} \\
94.1-103.7^{2} \\
100.2-115.5^{3} \\
\end{array}$ \\
\hline & & $\begin{array}{l}\text { Boot/head } \\
1.28-1.92\end{array}$ & 84-101 & $\begin{array}{c}83.3-96.5^{1} \\
84.4-94.1^{2} \\
84.9-100.2^{3}\end{array}$ \\
\hline & \multirow[b]{2}{*}{ Warm season grasses } & $\begin{array}{l}\text { Pre-boot } \\
1.6-2.24\end{array}$ & $90-104$ & $\begin{array}{c}89.9-103.1^{1} \\
89.3-98.9^{2} \\
92.5-107.9^{3}\end{array}$ \\
\hline & & $\begin{array}{c}\text { Mature/head } \\
0.96-1.6\end{array}$ & $62-90$ & $\begin{array}{l}76.8-89.9^{1} \\
79.6-89.3^{2} \\
77.2-92.5\end{array}$ \\
\hline \multirow{2}{*}{ Hackmann et al., 2008} & Cool season grasses & 1.96 & 90 & $\begin{array}{c}97.3^{1} \\
94.7^{2} \\
101.1^{3} \\
\end{array}$ \\
\hline & Warm season grasses & 2.88 & 109 & $\begin{array}{l}116.2^{1} \\
108.6^{2} \\
123.2^{3}\end{array}$ \\
\hline Lewis et al., 2006 & Tripsacum dactyloides & 2.92 & 100.0 & $\begin{array}{l}117.0^{1} \\
109.2^{2} \\
124.1^{3}\end{array}$ \\
\hline Albayrak et al., 2011 & $\begin{array}{c}\text { Agropyron intermedium } \\
\text { Host. Beauv. }\end{array}$ & $\begin{array}{c}1.62 \\
\text { (two years } \\
\text { average value) }\end{array}$ & 89.2 & $\begin{array}{l}90.3^{1} \\
89.6^{2} \\
93.0^{3}\end{array}$ \\
\hline DairyOne, 2019 & $\begin{array}{c}\text { Grass hay } \\
\text { (data from the years of } \\
2000-2018 \text { ) }\end{array}$ & $\begin{array}{c}1.74 \\
\text { (average of } 94301 \\
\text { samples) }\end{array}$ & $\begin{array}{c}89.4 \\
\text { (average of } 92571 \\
\text { samples) }\end{array}$ & $\begin{array}{l}92.8^{1} \\
91.4^{2} \\
95.9^{3}\end{array}$ \\
\hline
\end{tabular}

${ }^{+}$It was calculated by dividing the protein content from the open access literature to 6.25

${ }^{1}$ Predicted RFV by Equation 1

${ }^{2}$ Predicted RFV by Equation 2

${ }^{3}$ Predicted RFV by Equation 3 
It was not expected to estimate the exact experimental results with the empirical equations. Nevertheless, it is clear that the predictions were quite close to the actual data. However, the Fisher's F test, for the 13 samples provided in Table 5, manifested that the actual and the predicted RFVs were not different at the significance level of $5 \%$ since having the p values for Equations 1, 2 and 3 were 0.96, 0.13 and 0.58 respectively $(\mathrm{P}>0.05)$. Actually, RFV index classified the forages as grade $1(>140)$, grade 2 (124140), grade 3 (101-123), grade 4 (83-100), and grade 5 or supreme, good and premium $(<83)$ (Rohweder et al., 1978) according to the limit range where the calculated RFV value is to be included. Therefore, even if the predictions from the new equations were not exactly overlapped with the actual ones, they were within the same grading class. Rohweder et al. (1978) reported another definition and physical descriptions for grass grading. According to this specification, the best pure grass hays appeared to have a grade not higher than grade 2. That is why, the grade as "prime" for grasses is with the range of the second grading step of legumes. Different grazing animals have different feed needs. Dairy cattle, cows in late-term pregnancy, heavily lactating beef cattle, pregnant heifers, and cattle in poor condition need hay of higher RFV (Nelson, 2010) and protein content. Thus, the knowledge on the variation of RFV of native pastures depending on the phenological stages and its relationships between the mineral compositions will give opportunities to the farmers to manage the harvest or grazing. Even, adjusting the stocking rate that is vital for the sustainability of native pastures might be possible with the help of new RFV equations provided here.

\section{Conclusion}

Relative feed value (RFV) is an evaluation criteria not only for marketing but also to express the forage quality. It ranks the forages based on energy. However, two forages with the same RFV do not always perform the same because the RFV index does not reveal any information on protein content. Whereas, the forage evaluation should include a complete information of nutrient composition including digestibility and crude protein (CP) because the energy requirement of livestock fed on low-quality native pastures increases and energy supplementation to diet is needed (Martin and Hibberd, 1990). Since the new PLSR models developed in the current study based on forage nitrogen content, their predictions may give more explanation about quality and protein content also. Moreover, because of the reflection of the multivariate relation between the other minerals, the PLSR based equations are more valuable and informative. However, it should not be ignored that the natural pasture composition contains many species including legumes. Therefore, the accuracy and so the effectiveness of such equations should also be supported by the future animal experiments that contain different plant families. That knowledge will improve the reliability and accuracy of the new equations in preparing rations for different animal requirements.

\section{REFERENCES}

[1] Albayrak, S., Türk, M., Yüksel, O., Yılmaz, M. (2011): Forage Yield and the quality of perennial legume grass mixtures under rainfed conditions. - Not. Bot. Horti Agrobot. ClujNa 39(1): 114-118.

[2] Ball, D. M., Collins, M., Lacefield, G. D., Martin, N. P., Mertens, D. A. et al. (2001): Understanding Forage Quality. - American Farm Bureau Federation, Park Ridge, IL. 
[3] Brown, W. F., Pittman, W. D. (1991): Concentration and degradation of nitrogen and fiber fractions in selected tropical grasses and legumes. - Trop Grassl 25: 305-312.

[4] Caddel, J., Allen, E. (1994): Forage Quality Interpretations. - Oklahoma Coop. Extension Service Facts F-2117, Oklahoma St. Univ., Stillwater, OK.

[5] Cogswell, C., Kamstra, L. D. (1976): The stage of maturity and its effect upon the chemical composition of four native range species. - J. Range Manag 29(6): 460-463.

[6] DairyOne (2019): https://dairyone.com/analytical-services/feed-and-forage/feedcomposition-library/interactive-feed-composition-library. - Accessed 08.07.2019.

[7] Fulgueira, C. L., Amigot, S. L., Gaggiotti, M., Romero, L. A., Basilico, J. C. (2007): Forage quality: techniques for testing. - Fresh Produce 1(2): 121-131.

[8] Goering, H. K., Van Soest, P. J. (1970): Forage Fiber Analysis (Apparatus, Reagents, Procedures and Some Applications). - USDA Agricultural Handbook, No. 379. Agricultural Research Service, US, Dep. Agric., Washington, DC.

[9] Greene, L. W. (1997): Mineral composition of southern forages. - Proc. Mid-South Ruminant Nutr. Conf., 1-2 May, Dallas, TX.

[10] Hackmann, T. J., Sampson, J. D., Spain, J. N. (2008): Comparing relative feed value with degradation parameters of grass and legume forages. - J Anim Sci 86(9); 2344-2356.

[11] Henning, J. C., Lacefield, G. D., Donna Amaral, P. D. (1999): Interpreting Forage Quality Reports. - Online publication ID-101. Cooperative Extension Service, University of Kentucky, College of Agriculture, Lexington, KY.

[12] Hodgson, D. R., McKeever, K., McGowan, C. M. (2014): The Athletic Horse: Principles and Practice of Equine Sports Medicine. - In: Hodson, D. R. et al. (eds.) The Athletic Horse. $2^{\text {nd }}$ Ed. Saunders, Elsevier Inc, Philadelphia.

[13] Hoffman, P. C., Lundberg, K. M., Bauman, L. M., Randy, D. S. (2003): The Effect of maturity on NDF digestibility. - Focus on Forage 5: 15.

[14] Hopke, P. K. (2003): The evolution of chemometrics. - Anal Chim Acta 500: 365-377.

[15] Humphreys, M. O. (1989): Water-soluble carbohydrates in perennial ryegrass breeding. III. Relationships with herbage production, digestibility and crude protein-content. - Grass and Forage Sci 44: 423-430.

[16] Jones, J. B., Wolf, B., Mills, H. A. (1991): Interpretation of results. In: Plant Analysis Handbook - a practical sampling, preparation, analysis, and interpretation guide. - MicroMacro Publishing Inc., USA.

[17] Kappel, L. C., Morgan, E. B., Kilgore, L., Ingraham, R. H., Babcock, D. K. (1983): Seasonal changes of mineral content of Southern forages. - J Dairy Sci 68: 1822-1827.

[18] Kjeldahl, J. (1883): Neue Methode zur Bestimmung des Stickstoffs in organischen Körpern (New method for the determination of nitrogen in organic substances). - Fresenius Z Anal Chem. 22(1): 366-383.

[19] Lacefield, G. D., Henning, J. C., Smith Jr, S. R. (2012): Forages for Beef Cattle. publications ID-108/2. University of Kentucky, Lexington, KY.

[20] Lewis, J. S., Ditchkoff, S. S., Lin, J. C., Muntifering, R. B., Chappelka, A. H. (2006): Nutritive quality of big bluestem (Andropogon gerardii) and eastern gamagrass (Tripsacum dactyloides) exposed to tropospheric ozone. - Rangeland Ecol Manag 59: 267-274.

[21] Linn, J., Kuehn, C. (1997): The effects of forage quality on performance and cost of feeding lactating dairy cows. - Proc. of Western Canadian Dairy Seminar, University of Alberta, Edmonton, Canada.

[22] Mariotti, F., Tomé, D., Mirand, P. P. (2008): Converting nitrogen into protein - beyond 6.25 and Jones' factors. - Crit Rev Food Sci Nutr 48(2): 177-184.

[23] Martin, S. L., Hibberd, C. A. (1990): Intake and digestibility of low-quality native grass hay by beef cows fed graded levels of soybean hulls. - J Anim Sci 68: 4319.

[24] Mayland, H. F., Shewmaker, G. E., Harrison, P. A., Chatterton, N. J. (2000): Nonstructural carbohydrates in tall fescue cultivars: relationship to animal preference. - Agron J 92: 1203-1206. 
[25] Moore, J. E., Undersander, D. J. (2002): Relative forage quality: an alternative to relative feed value and quality index. - Proc $13^{\text {th }}$ Annual Florida Ruminant Nutrition Symposium. Jan. 11-12, 2002, Gainesville, FL, pp. 16-32.

[26] Nelson, M. (2010): Your Beef Cattle Operation. - In: Nelson, M. (ed.) The Complete Guide to Small-Scale Farming: Everything You Need to Know About Raising Beef and Dairy Cattle, Rabbits, Ducks, and Other Small Animals. Chapter 9. - Atlantic Publishing Company, Ocala, FL.

[27] Niemann, G. J., Pureveen, J. B. M., Gert, B. E., Poorter, H., Boon, J. J. (1992): Differences in relative growth rate in 11 grasses correlate with differences in chemical composition as determined by pyrolysis mass spectrometry. - Oecologia 89: 567-573.

[28] Pearson, C. J., Ison, R. L. (eds.) (1997): Agronomy of Grassland Systems. $2^{\text {nd }}$ Ed. Cambridge University Press, Cambridge, UK.

[29] Peeters, A. (2004): Wild and sown grasses. Profiles of a temperate species selection: ecology, biodiversity and use. - FAO \& Blackwell Publishing, Rome \& Hoboken, NJ.

[30] Perez-Arevalo, J. J., Callejon-Ferre, A. J., Velazquez-Marti, B., Suarez-Medina, M. D. (2015): Prediction models based on higher heating value from the elemental analysis of neem, mango, avocado, banana, and carob trees in Guayas (Ecuador). - J Renew Sustain Energy 7: 053122.

[31] Poorter, H., Bergkotte, M. (1992): Chemical composition of 24 wild species differing in relative growth rate. - Plant Cell Environ 15: 221-229.

[32] Rayburn, E. B. (1997): Forage Quality-Minerals. - Service ID-5016. West Virginia University Extension, Morgantown, WV.

[33] Rohweder, D. A., Barnes, R. F., Jorgensen, N. (1978): Proposed hay grading standards based on laboratory analyses for evaluating quality. - J Anim Sci 47: 747-759.

[34] Sáez-Plaza, P., Michałowski, T., Navas, M. J., Asuero, A. G., Wybraniec, S. (2013): An overview of the kjeldahl method of nitrogen determination. Part I. Early history, chemistry of the procedure, and titrimetric finish. - Crit Rev Anal Chem 43(4): 178-223.

[35] Schroeder, J. W. (1996): Quality Forage for Maximum Production and Return. Educational Materials from North Dakota State University Agriculture and University Extension ID AS-1117, Fargo, ND.

[36] Stone, B. A. (1994): Prospects for improving the nutritive value of temperate, perennial pasture grasses. - New Zeal J Agr Res 37: 349-363.

[37] Sturla, F. (1960): Eggjahvítumagn og lostaetni túngrasa (Protein content and palatability of cultivated grasses in Iceland). - Atvinnudeild Háskólans, Rit landbúnaðardeildar BFlokkur 12: 27.

[38] Undersander, D., Mertens, D. R., Thiex, N. (1993): Forage Analyses Procedures. National Forage Testing Association (NFTA), Omaha, NB.

[39] Ward, R. (2008): Relative Feed Value (RFV) vs. Relative Forage Quality (RFQ). Cumberland Valley Analytical Services, Inc., Hagerstown.

[40] Weiss, W. P., Eastridge, M. L., Underwood, J. F. (2012): Forages for Dairy Cattle. - Ohio State University, Columbus, OH. Extension ID-AS-0002-99.

[41] Yeniay, Ö., Göktaş, A. (2002): A comparison of partial least squares regression with other prediction methods. - Hacet J Math Stat 31: 99-111. 